\title{
Lidil
}

Revue de linguistique et de didactique des langues

$50 \mid 2014$

Variation stylistique et diversité des contextes de socialisation

\section{Semen, $\mathrm{n}^{\circ} 36$, « Les nouveaux discours publicitaires »}

novembre 2013

\section{Carole Calistri}

\section{OpenEdition \\ Journals}

Édition électronique

URL : http://journals.openedition.org/lidil/3667

DOI : 10.4000/lidil.3667

ISSN : 1960-6052

Éditeur

UGA Éditions/Université Grenoble Alpes

\section{Édition imprimée}

Date de publication : 15 décembre 2014

Pagination : 219-221

ISBN : 978-2-84310-287-5

ISSN : $1146-6480$

Référence électronique

Carole Calistri, «Semen, n 36, « Les nouveaux discours publicitaires » », Lidil [En ligne], 50 | 2014, mis en ligne le 15 juin 2016, consulté le 22 septembre 2020. URL : http://journals.openedition.org/lidil/ 3667 ; DOI : https://doi.org/10.4000/lidil.3667 
entre les deux disciplines et le monde social. Pour réagir à la doxa qui «tyrannise l'histoire scolaire», une «grammaire du questionnement scolaire de l'histoire» est proposée. Le dernier texte du premier axe illustre les pratiques d'interprétation des œuvres littéraires au collège genevois (équivalent du lycée) et leurs implications.

Les textes du second axe mettent à l'épreuve les concepts et les méthodes des didactiques. Le premier s'intéresse à l'École de culture générale (enseignement secondaire post-obligatoire genevois) et s'interroge sur l'impact de l'introduction dans le curriculum de l'argumentation en français et en physique. Le second texte porte sur les objets d'enseignement en français et sur les méthodes pour les appréhender en contexte de classe d'une part, de formation d'enseignants d'autre part. Le suivant s'intéresse aux tâches, aux exercices et aux problèmes dans trois disciplines (langue étrangère, mathématiques et sciences), avec l'objectif de cerner la culture disciplinaire de chacune d'entre elles. L'avant-dernier texte aborde la fonction didactique de la justification en lecture/compréhension et en sciences de la nature. Cette étude s'inscrit dans le programme pluridisciplinaire en didactique du Réseau Maison des petits, à Genève. Enfin, le dernier texte porte sur la diversité des approches en didactique des mathématiques dans l'enseignement primaire en Suisse romande.

Sandra Canelas-Trevisi Université Grenoble Alpes, LIDILEM et GRAFE

Semen, $n^{\circ}$ 36, «Les nouveaux discours publicitaires», nov. 2013

Neuf contributions (France, Suisse, Italie, Chili) coordonnées par M. Bonhomme font le point sur les modalités d'inscription de la publicité. On pourrait parcourir les articles proposés avec le prisme du masquage/ dévoilement ou de l'effacement/déplacement des trois «objets» de la publicité : produit, consommateur, annonceur. M. Bonhomme analyse la plasticité du discours publicitaire (d.p.) s'adaptant à son environnement technique et social, pointant la perspective interactive affichée des nouveaux messages publicitaires. J.-C. Soulages cible, lui, les imaginaires («images de la réalité, mais en tant que cette image interprète la réalité, la fait entrer dans un univers de signification », Charaudeau, 2005 , p. 158) et ce qu'ils disent d'un produit devenu un bienfait, d'un 
consommateur mué en spectateur, que flatte la connivence distillée par les scenarii carnavalesques, mais que la publicité affirme doté d'un libre-arbitre.

K. Berthelot, C. de Montety et V. Patrin-Leclère lisent les métamorphoses du d.p. à travers les concepts de publicitarisation, publicitarité, dépublicitarisation et hyperpublicitarisation, qui offrent la possibilité de décrire avec un grain très fin les mouvements qui font sortir la publicité des cadres où elle se tenait et lui permettent d'envahir l'espace médiatique. Elles montrent le paradoxe de l'efficacité, qu'il s'agisse de phénomènes visant à dissimuler l'intention publicitaire ou, au contraire, à l'expanser.

L. Guellec explore le territoire du branded content dont le discours se caractérise par le ciblage sur la marque et non plus sur le produit et se développe dans des espaces plus larges que celui des media publicitaires traditionnels. Elle met en valeur la recherche esthétique qui s'y trouve en évoquant un «dispositif de fiction capable de tenir le public en haleine» et signale la confrontation qui se réalise alors entre brand content et publicité déguisée, «discours ouvert» et «discours couvert» (Bô \& Guével, 2009). Devenue l'objet du d.p., la marque produit, par le biais de dispositifs interactifs, des promesses d'être (un pilote, un artiste...) davantage que d'avoir(s), fait du client un consom'acteur comme le nomment C. Duteil-Mougel et D. Tsala-Effa qui examinent quelle sorte de conversation se développe entre marques et consommateur. Le dispositif est manipulatoire, avec des exemples sur les murs Facebook de Coca-Cola ou Danette où, s'il n'est pas directement question de vanter un produit, l'objectif n'en demeure pas moins de créer une addiction grâce aux participations interactives (jeux, «like» de Facebook). C'est efficace pour évaluer la notoriété, mais l'impossibilité de répondre à chaque post diminue les bénéfices attendus.

S. Equoy-Hutin se penche sur la «buzzabilité» du d.p. avec l'exemple d'une photographie d'enfants en T-shirts sur une plage pour La Redoute, dont le second plan montre un homme nu sortant de l'eau. L'article analyse le corpus mouvant de ce buzz, traquant la dépublicitarisation qui permet, en convoquant l'activité journalistique, de diluer les «ruptures sémiotiques» entre publicité et journalisme et de faire croire à un «paraître dialogique» (Adam \& Bonhomme, 2005, p. 37) avec les internautes.

O. Aïm s'intéresse au marketing viral, panoptique foucaldien. Son analyse envisage un modèle apostolique («postal», disséminatoire) et un modèle érotique (en référence à Socrate et à l'idéal habermassien 
du dialogue). Il indique que ce marketing «entérine l'idée que chacun est apte à se faire l'apôtre de la marque» et convertit la menace de contamination en idéal de la contagion. Intégration ou ségrégation dans la publicité ethnique (le spot Zakia Halal) est la question posée par L. Santone. Est-ce simplement un autre territoire que la publicité conquiert? une prise en compte du métissage?

Un article consacré aux campagnes gouvernementales de lutte contre les violences faites aux femmes clôt le dossier. M. Hernandez Orellana et S. Kunert comparant France et Chili posent la question de la pertinence du format publicitaire nécessairement stéréotypique en raison du caractère ramassé du message.

La publicité déborde son espace initial pour devenir «supplétif du politique» (Soulages) et la politique emprunte les formats de la publicité. Le mouvement actuel déplace les repères : la marque à la place du produit et le consommateur à la place de l'annonceur.

C'est un numéro d'utilité publique dont on peut espérer qu'il soit l'appui de nombreuses initiatives didactiques pour donner aux citoyens le moyen de repérer l'artifice et de résister à la manipulation qui, pour être de mieux en mieux dissimulée, n'en est, bien sûr, que plus dangereuse.

Dans les Varia, H. Vassiliadou montre «c'est-à-dire» comme embrayeur d'énonciation, prévenant une fausse inférence que l'interlocuteur serait tenté de faire mais fonctionnant aussi comme marque phatique ou de réfutation. Ceci pourra intéresser les études sur le facework goffmanien.

Carole Calistri ESPE de Nice

Semen, $\mathrm{n}^{\circ}$ 37, "Approches discursives des récits de soi », coordonné par Sandra Nossik, avril 2014

À la lecture de ce numéro de Semen, les locutions ont carambolé dans ma tête et déroulé le fil de leurs usages disciplinaires. J'ai pensé aux «histoires de vie» (Leahey \& Helle, 2003), aux « récits de vie» (Oraofiamma, 2008) que l'ethnologie, la sociologie et les sciences de l'éducation, dans les traces de l'école de Chicago et selon une tradition méthodologique biographique (entre autres, Peneff, 1990), ont constitué 